\title{
Treatment with closed manipulation and functional bracing of a humeral diaphysis refracture with implant failure: A case report
}

\author{
Ali Ersen, Atakan Guvendiren, Ozgur Yazici
}

\begin{abstract}
Introduction: Implant failures and loss of the reduction are the main complications of open reduction and internal fixation with plate and screws. If those complications occur, revision surgery is the standard treatment. We would like to present a case where implant failure and loss of reduction of humerus diaphyseal fracture is treated with close reduction and Sarmiento bracing. Case Report: A 28 -year-old male was diagnosed with closed humeral diaphysis fracture without neuromuscular injury due to traffic accident. He was treated with open reduction and internal fixation with plate and screws. After three months, he was presented to outpatient clinic with severe pain after minor trauma. Implant failure with screw breakage and loss of reduction with angulation were obvious on plane X-ray. Instead of revision surgery, it was treated with closed reduction and Sarmiento bracing. Conclusion: Functional bracing can be appropriate for humeral diaphysis non-unions with implant failure when the patient is not suitable for surgery.
\end{abstract}

Ali Ersen ${ }^{1}$, Atakan Guvendiren², Ozgur Yazici²

Affiliations: ${ }^{1}$ Istanbul University Medical Faculty, Department of Orthopedics and Traumatology, Istanbul; ${ }^{2}$ Mardin Kiziltepe State Hospital Department of Orthopedics and Traumatology, Mardin.

Corresponding Author: Dr. Ali Ersen, Istanbul University Medical Faculty, Department of Orthopedics and Traumatology, ISTANBUL; Ph: +905357409795; Email: ali_ ersen@hotmail.com

Received: 27 April 2013

Accepted: 23 May 2013

Published: 01 October 2013
Keywords: Humerus diaphysis non-union, Bracing, close reduction

$* * * * * * * * *$

Ersen A, Guvendiren A, Yazici O. Treatment with closed manipulation and functional bracing of a humeral diaphysis refracture with implant failure: A case report. International Journal of Case Reports and Images 2013;4(10):582-585.

$* * * * * * * * *$

doi:10.5348/ijcri-2013-10-385-CII-14

\section{INTRODUCTION}

Most of the humeral fractures heal uneventfully with conservative methods. Although the operative treatment of fractures has improved the care of many patients, it may also produce undesirable consequences. Loss of fixation and non-union are two major complications of humeral fractures treated with open reduction and plate fixation.

Non-union rates of humeral shaft fractures are reported $10-15 \%$ with surgical treatment methods $[1,2]$. Open fractures, segmental fractures, highly comminuted fractures, transvers fractures and impaired host healing (diabetes, smoking and malnutrition) are the basic risk factors of humerus shaft non-union. If a humeral shaft non-union is diagnosed, conservative treatment methods are not recommended because of poor results reported [3]. If previous surgery has been performed hardware removal, debriding the fibrous tissue, bone grafting and fixation should be done to achieve a solid union. External fixation should be necessary in cases of infected nonunions where internal devices are not useful for fixation. 
Loss of fixation is the result of inadequate surgical technique. To achieve stability with plate osteosynthesis, the plate must have adequate thickness and length. By compression plating at least four screws holes must overlie each major distal end proximal fragments and equal length of plate and number of screws should be on both sides of fracture [4]. Obvious loss of stability on radiographs or clinical examination is a clear evidence of non-union and should be re-evaluated for revision surgery. We would like to present a case where a humeral shaft fracture treated with inadequate plating technique resulted with loss of fixation and treated with close manipulation and bracing without hardware removal.

\section{CASE REPORT}

A 28-year-old male diagnosed with closed humerus shaft fracture due traffic accident without neurovascular injury. He was treated with open reduction and plate fixation at another hospital four months ago (Figure $1 \mathrm{~A}-\mathrm{B})$. Postoperative period was uneventful. However, there was a lack of union after 12 weeks (Figure 2). He was presented to our outpatient clinic with severe pain after a minor trauma. The plain radiographs revealed a nonunion of humerus shaft fracture with loss of reduction and implant failure with a broken screw (Figure 3). There was no evidence of infection on clinical examination and C-reactive protein level was also normal. The patient was diagnosed with atrophic non-union with implant failure and offered revision surgery with implant removal, bone grafting and fixation with a longer and thicker plate. However, the patient did not accept revision surgery demanded conservative treatment. Closed manipulation (Figure 4A-B) under sedation and a Sarmiento type brace cast was applied. Although the reduction was good, the patient was informed of high risk of ineffectiveness of this treatment method. During monthly follow-up, there was no loss of reduction again, and at the fourth month follow-up after closed manipulation solid bony union was achieved without any deformity (Figure $5 \mathrm{~A}-\mathrm{B}$ ).

\section{DISCUSSION}

Humerus non-unions can be severely disabling and the treatment should be different then acute fracture treatment. Although many authors suggested debridement, open reduction and plate fixation for nonunions of the humeral shaft inadequate plating technique is the main reason of failure $[5,6]$. In order to have enough stability at the non-union site, double plating, one on the lateral side and one on the posterior side is recommended [7]. Bone grafting is offered to enhance the biological environment [8].

Functional bracing for the humeral shaft provides high union rates but it is not the recommended treatment option for humeral diaphyseal non-unions. On elderly
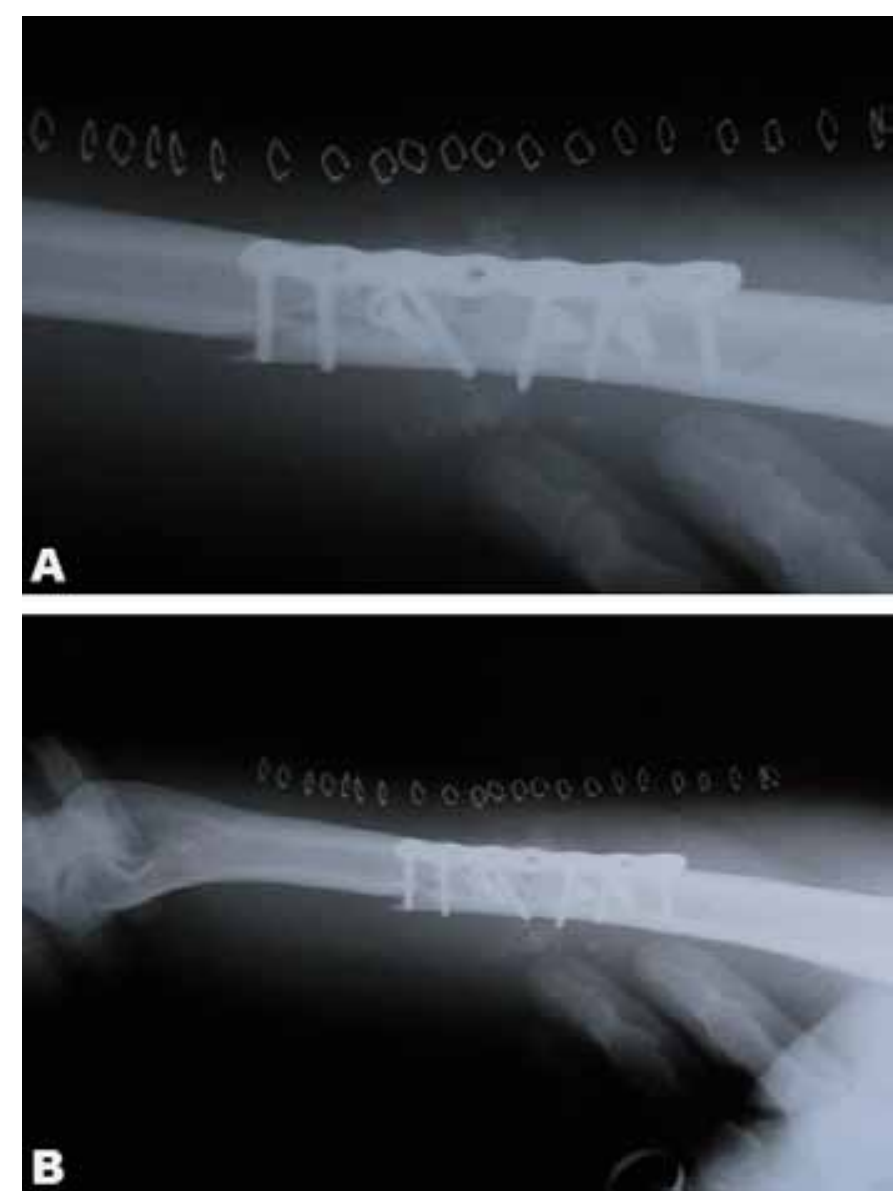

Figure 1: (A, B) Inappropriate plate fixation of humeral diaphysis fracture.

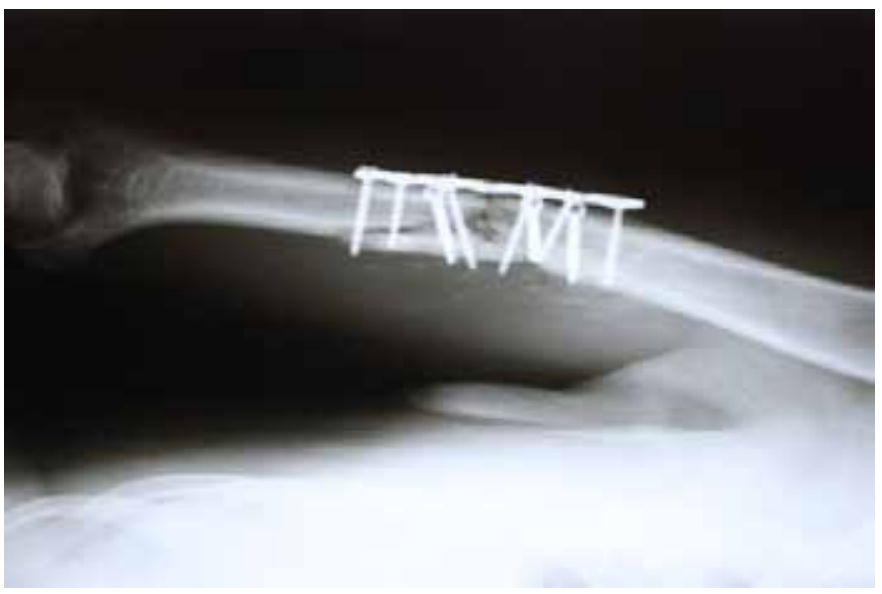

Figure 2: After 12 weeks lack of healing.

patients with low demands functional bracing could be considered as an option to support the limb but on active young patient bony union must be achieved in order to restore function [9]. We could not find any paper in literature about the treatment of previously surgically intervened humerus diaphyseal non-union with implant failure treated with closed reduction and functional bracing. 


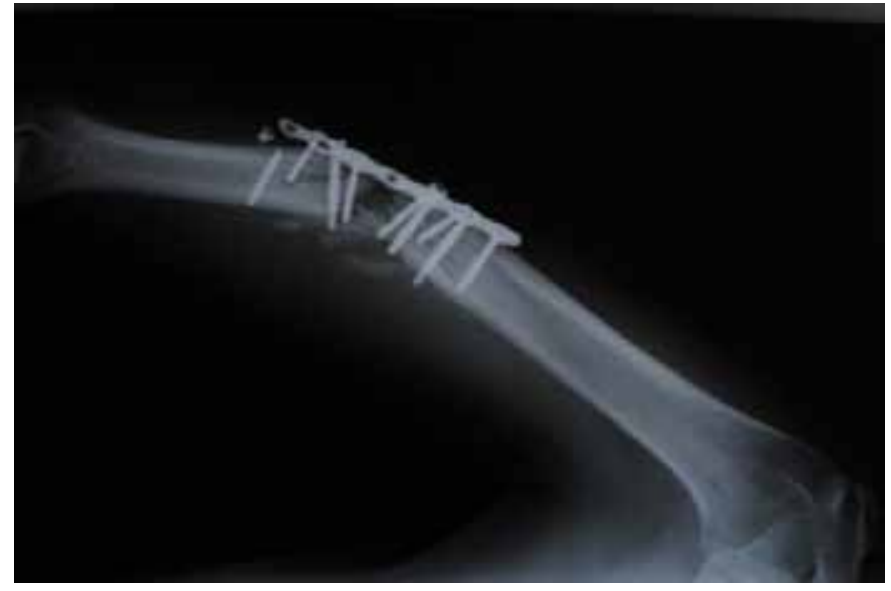

Figure 3: Implant failure with loss of reduction and broken screw.
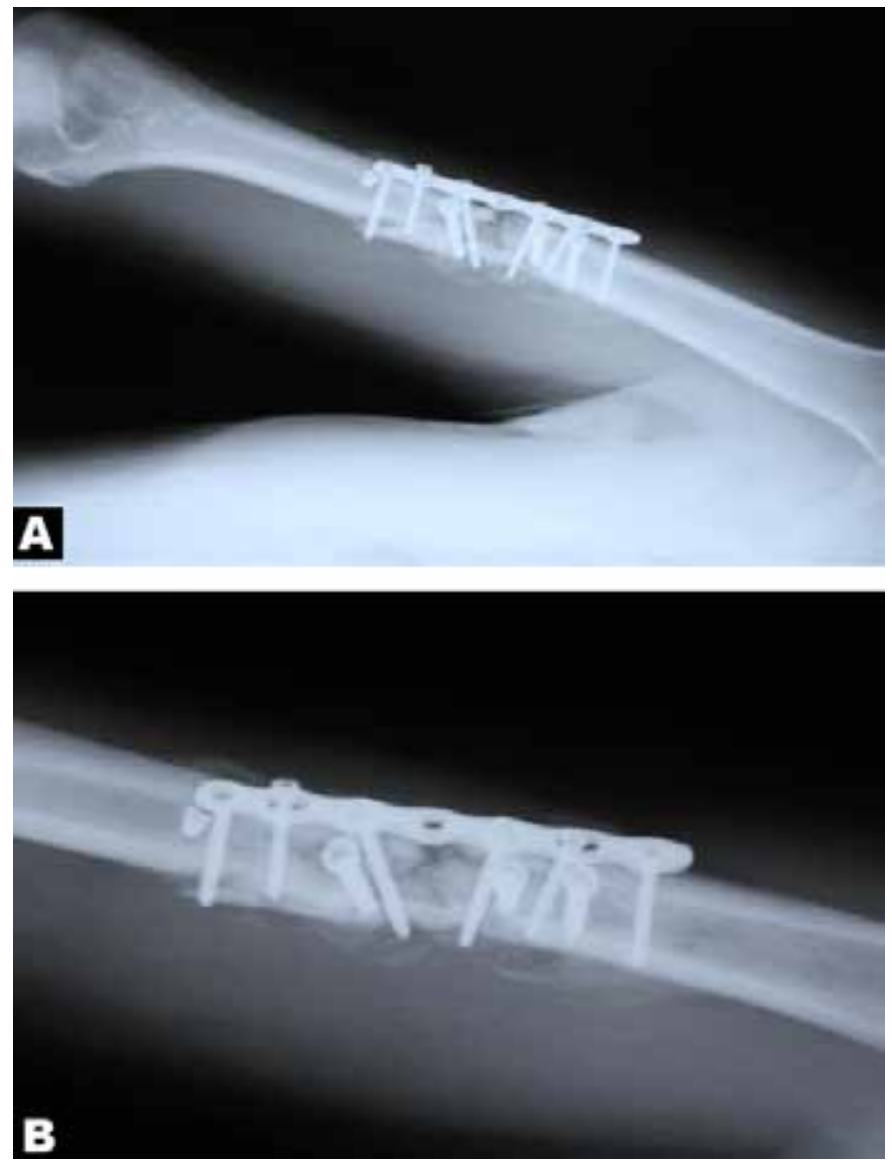

Figure 4: (A, B) Implant after close reduction.

\section{CONCLUSION}

The case of our patient illustrates that functional bracing can be appropriate for humerus diaphyseal non-unions with implant failure when the patient is not suitable for surgery.
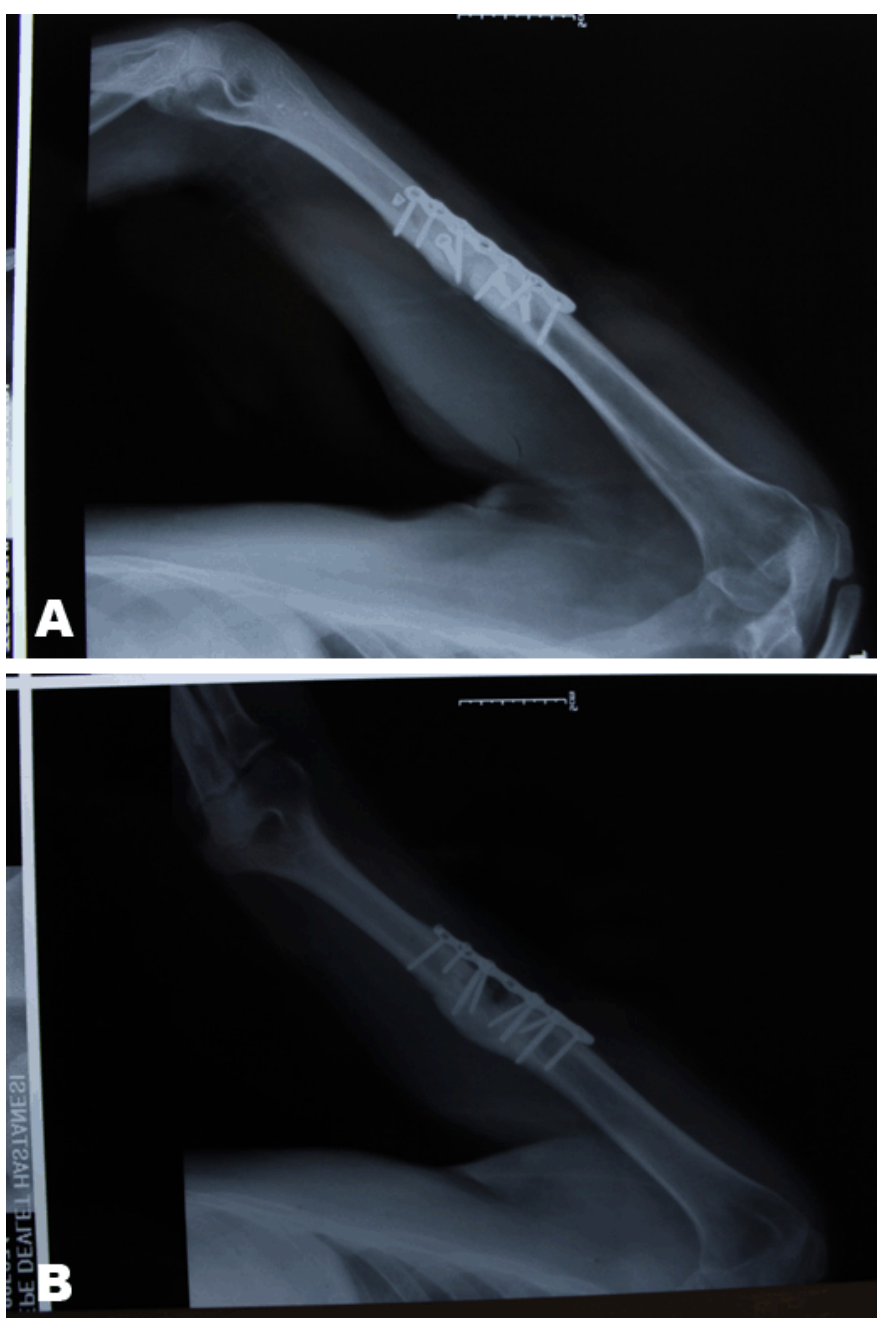

Figure 5: (A, B) After four months solid union was achieved.

$* * * * * * * * *$

\section{Author Contributions}

Ali Ersen - Substantial contributions to conception and design, Acquisition of data, Drafting the article revision it critically for important intellectuel content, Final approvel of the version to be published

Atakan Gunevdiren - Substantial contributions to conception and design, Acquisition of data, Drafting the article revision, Final approvel of the version to be published

Ozgur Yazici - Substantial contributions to conception and design, Acquisition of data, Drafting the article, Final approvel of the version to be published

\section{Guarantor}

The corresponding author is the guarantor of submission.

\section{Conflict of Interest}

Authors declare no conflict of interest. 


\section{Copyright}

(C) Ali Ersen et al. 2013; This article is distributed under the terms of Creative Commons attribution 3.0 License which permits unrestricted use, distribution and reproduction in any means provided the original authors and original publisher are properly credited. (Please see www.ijcasereportsandimages.com/copyright-policy.php for more information.)

\section{REFERENCES}

1. Sarmiento A, Zagorski JB, Zych GA, Latta LL, Capps CA. Functional bracing for the treatment of fractures of the humeral diaphysis. J Bone Joint Surg Am 2000;82(4):478-6.

2. Marti RK, Verheyen CC, Besselaar PP. Humeral shaft nonunion: evaluation of uniform surgical repair in fifty-one patients. J Orthop Trauma 2002;16(2):10815 .

3. Anglen JO. Enhancement of fracture healing with bone stimulators. Failed internal fixation. Tech Orthop 2002;17:506-14.
4. Anglen JO, Archdeacon MT, Cannada LK, Herscovici D Jr, Ostrum RF. Avoiding complications in the teratment of humeral fractures. Instr Course Lect 2009;58:3-11.

5. Ring D, Perey BH, Jupiter JB. The functional outcome of operative treatment of ununited fractures of the humeral diaphysis in older patients. J Bone Joint Surg Am 1999;81(2):177-90.

6. Foster RJ, Dixon GL Jr, Bach AW, Appleyard RW, Green TM. Internal fixation of fractures and nonunions of the humeral shaft. Indications and results in a multi-center study. J Bone Joint Surg Am 1985;67(6):857-64.

7. Murray WR, Lucas DB, Inman VT. Treatment of nonunion of fractures of the long bones by the two-plate method. J Bone Joint Surg Am 1964;46:1027-48.

8. Hierholzer C, Sama D, Toro JB, Peterson M, Helfet DL. Plate fixation of ununited humeral shaft fractures: effect of type of bone graft on healing. J Bone Joint Surg Am 2006;88(7):1442-7.

9. Rosen, H. Management of nonunions and malunions in long bone fractures. In Comprehensive Care of Orthopaedic Injuries in the Elderly, pp. 489-511. Edited by J. D. Zuckerman. Baltimore, Urban and Schwarzenberg, 1990.
Access full text article on other devices

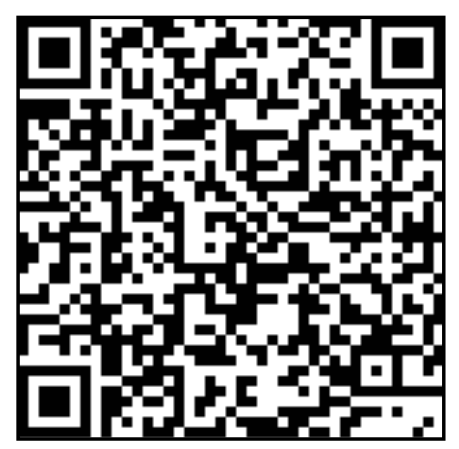

Access PDF of article on other devices

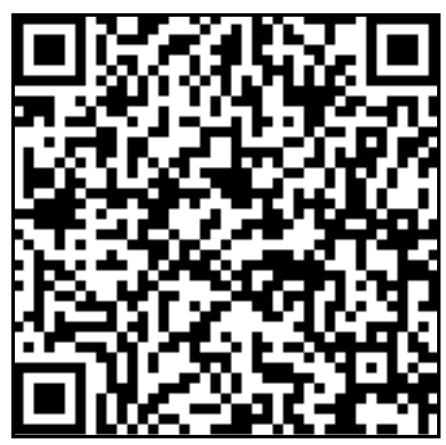

